\title{
Endovascular Management of Acute Ischemic Stroke
}

\author{
Stavropoula I. Tjoumakaris, \\ Pascal M. Jabbour, Aaron S. Dumont, \\ L. Fernando Gonzalez and Robert H. Rosenwasser \\ Thomas Jefferson University, Philadelphia, \\ USA
}

\section{Introduction}

Stroke is a major cause of serious, long-term disability and the third leading cause of death in the United States ${ }^{1}$. According to the World Health Organization, 15 million people suffer a stroke worldwide annually. Of those, one third do not survive and another third is left with a significant neurological deficit. The majority of these events are ischemic $(87 \%)$, as opposed to intracerebral (10\%) and subarachnoid hemorrhages $(3 \%)^{1}$. Management of acute ischemic stroke was previously geared toward prevention, supportive care, and rehabilitation. Over the past few decades, however, the medical management of stroke has progressed exponentially, beginning with the US Food and Drug Administration (FDA) approval of tissue plasminogen activator (r-TPA, alteplase) in 1996. Intravenous administration of r-TPA within a limited 3-hour window from symptom onset has shown a significant improvement in patient outcome at 3 months and at one year following an acute cerebrovascular event. ${ }^{2}$ Current stroke guidelines have extended the therapeutic r-TPA administration window to 4.5 hours.

The intra-arterial (IA) injection of therapeutic agents was first published nearly 60 years ago, when Sussman and Fitch described the IA treatment of acute carotid occlusion with fibrinolysin injection in 1958. ${ }^{3}$ It was not until the late 1990's that the endovascular management of acute stroke experienced exponential progress and development. Recent advances in endovascular techniques have increased the therapeutic window of r-TPA administration and introduced new agents such as reteplase and abciximab. Furthermore, the use of IA devices for clot retrieval and vessel recanalization has revolutionized the neuroendovascular management of acute ischemic stroke.

\section{Patient selection}

The goal of endovascular management of acute ischemic stroke is to enhance the survival of local ischemic brain tissue (penumbra) and limit the extent of infarcted brain parenchyma. An initial evaluation with a non-contrast computerized tomography (CT) head scan is necessary. In a retrospective review of 85 patients from the Penumbra Pivotal 
Stroke Trial, Goyal and colleagues found that a baseline CT scan by ASPECTS score $>7$ (Alberta Stroke Program Early CT Scale) had a $50 \%$ chance of a favorable clinical outcome with early recanalization ( $\mathrm{p}=0.0001)$. In addition, ASPECTS scores of less than 4 did not show clinical improvement regardless of endovascular recanalization ${ }^{4}$. Patients with large territorial infarcts on CT scan are at a higher risk for hemorrhagic conversion following treatment and are therefore poor candidates for endovascular therapy. ${ }^{5}$ In addition, the presence of an intra-parenchymal hematoma is a contraindication to endovascular recanalization. Lastly, the presence of a hyperdense MCA sign on the initial head CT does not have a significant prognostic value in patient outcome and vessel recanalization rates. ${ }^{6-8}$

Over the past decade, the clinical application of CT perfusion scans has facilitated the pretreatment evaluation of "salvageable" tissue. A scan consistent with a mismatch between cerebral blood volume (CBV, "core" cerebral lesion volume) and cerebral blood flow or mean transient time (CBF or MTT, "penumbra" lesion volume) is a favorable patient selection criterion. ${ }^{9}$ In our institution, a favorable CT perfusion scan may overcome the sixhour post-symptom onset time restriction.

Although patient age and initial National Institutes of Health Stroke Scale score (NIHSS) do not show statistically significant correlation with post-treatment intracranial hemorrhage (ICH), careful attention should be paid to both. ${ }^{5}$ In a recent retrospective review of 156 patients, Zacharatos and colleagues found that thrombolytic therapy (chemical or mechanical) showed a favorable clinical outcome versus supportive management in the 80 years and older age group ${ }^{10}$. However, patient co-morbidities are evaluated prior to treatment. Specifically, the presence of hyperglycemia, defined as blood sugar levels greater than $200 \mathrm{mg} / \mathrm{dl}$ within 24 hours from presentation, can significantly increase the likelihood of post-thrombolysis hemorrhagic conversion. ${ }^{5}$

Previous administration of intravenous tPA is not a contraindication to IA intervention. However, the hemorrhagic complications in these patients are significantly higher, especially if urokinase was the arterial agent. ${ }^{5}$ One must therefore clearly explain the risks and benefits of the procedure to the family and include them in the decision making process. Overall, endovascular intervention is an invaluable tool in the management of acute ischemic stroke. However, the duration of ischemia and the presence of viable ischemic tissue in excess of irreversibly damaged tissue are both critical factors in the successful management of acute stroke.

\section{Angiographic evaluation}

Initial angiographic evaluation of the patient's vasculature is of paramount importance for the establishment of the ischemic etiology and initiation of treatment. Thus far, the use of general anesthesia is preferred due to motion elimination contributing to procedural safety and efficacy ${ }^{11}$. However, newer studies suggest that conscious sedation or local anesthesia may lead to more favorable radiographic and clinical outcomes by decreasing time delay and cerebral ischemia from hypoperfusion ${ }^{11-13}$. Femoral access is established in the symptomatic lower extremity, if no vascular contraindications exist. A thorough examination of the cerebrovascular anatomy begins with the aortic arch. The brachiocephalic vessels are visualized and any proximal stenosis, irregularities or occlusion noted. Proximal vessel disease may require immediate treatment with balloon angioplasty 
and/or stenting to allow access to the intracranial pathology or may itself be the cause of the acute ischemic event.

Based on the patient symptomatology and pre-procedure imaging, selective catheterization of the carotid or vertebrobasilar circulation supplying the affected territory is performed. Attention is paid to the extracranial collateral circulation, the leptomeningeal anatomy, the circle of Willis, and overall global cerebral perfusion. Recent data showed that the grade of angiographic collaterals is a decisive factor for the degree of reperfusion and clinical improvement following endovascular intervention in acute ischemic stroke ${ }^{14}$.

The modality of treatment (for example IA thrombolysis, balloon angioplasty, stenting, clot retrieval mechanisms) is tailored to each individual case. At times, advanced age or significant atherosclerotic disease may limit treatment options.

\section{Intra-arterial chemical thrombolysis}

Over the past decade, several agents have been investigated for IA thrombolysis with variable dosages and administration routes. Overall, these drugs act by activating plasminogen to plasmin, which in turn degrades fibrin and its associated derivatives. Although studies targeting direct comparisons of the different agents have not yet been published, fibrin-specific agents, such as recombinant tissue plasminogen activator (r-tPA) and recombinant pro-urokinase (rpro-UK) have been widely studied and used most frequently. ${ }^{15}$

First-generation agents, such as streptokinase and urokinase, are non-fibrin selective and could therefore have greater systemic complications. ${ }^{16}$ Streptokinase, a protein derivative from group C beta-hemolytic streptococci, has a half-life of 16-90 minutes. It has an increased association with intracranial and systemic hemorrhages, and was therefore removed from the chemical armamentarium for the management of acute ischemic stroke.17 Urokinase, a serine protease, has a half-life of 14 minutes and dosage range of 0.02-2 million units. ${ }^{18}$

Second-generation agents have a higher fibrin-specificity and are most commonly studied in IA stroke management studies. Alteplase (r-tPA), also a serine protease, has a half-life of 3.5 minutes and a dosage range of 20-60 mg. ${ }^{18}$ The precursor of urokinase (rpro-UK) has a halflife of 7 minutes and may be favorable to r-tPA due to decreased side effects. Kaur and colleagues published potential neurotoxic properties of alteplase, such as activation of NMDA receptor in the neuronal cell-death pathway, amplification of calcium conductance, and activation of extracellular matrix metalloproteinases. ${ }^{19}$ These effects may facilitate exacerbation of cerebral edema, disturbance of the blood brain barrier, and development of ICH.

Third-generation agents, such as reteplase and tenecteplase, have longer half-lives (15-18 minutes) and theoretically favorable vessel recanalization and local recurrence rates. 16 Newer -generation agents are genetically engineered, such as Desmoteplase and Microplasmin (Thrombogenics, Heverlee, Belgium).

Besides their fibrinolytic properties, the aforementioned agents have prothrombotic effects by the production of thrombin during thrombolysis, and subsequent activation of platelets and fibrinogen.16 As a result, concomitant use of systemic anticoagulation during IA thrombolysis is recommended with caution to risk of ICH. The most widely used adjuvant systemic agent is heparin. Newer generation agents under the category of 
glycoprotein (GP) IIIb/IIa antagonist, such as Reopro (abciximab) and Integrilin (eptifibatide) are currently under investigation. Memon and colleagues reviewed 35 cases of adjunctive use of eptifibatide in salvage reocclusion and thrombolysis of distal thrombi with a single bolus of $180 \mu \mathrm{g} / \mathrm{kg}$. They reported a partial to complete recanalization of $77 \%$. However, incidence of post-operative hemorrhage was $37 \%$ and symptomatic in $14 \%$ of patients ${ }^{20}$.

\subsection{Anterior circulation}

\subsubsection{Middle cerebral artery}

Three major clinical trials evaluated the efficacy of IA thrombolysis in the Middle Cerebral Artery (MCA) circulation, specifically the PROACT I and II (Prolyse in Acute Cerebral Thromboembolism), and MELT trials (Middle Cerebral Artery Local Fibrinolytic Intervention Trial). Although IA thrombolysis shows a favorable outcome in the setting of acute ischemic injury, FDA approval has thus far been granted for its intravenous counterpart alone. ${ }^{21}$

In 1998, del Zoppo and colleagues presented a phase II clinical trial investigating the safety and efficacy of IA delivery of recombinant-pro-urokinase (rpro-UK) in acute MCA stroke, PROACT I. ${ }^{22}$ Following the exclusion of intracranial hemorrhage with a non-contrast head $\mathrm{CT}, 40$ patients were randomized for treatment of acute ischemic stroke within 6 hours of symptom onset. Cerebral angiography was performed, and M1 or M2 occlusions were treated with $6 \mathrm{mg}$ of rpro-UK $(\mathrm{n}=26)$ or placebo $(\mathrm{n}=14)$. All patients received a concomitant heparin bolus followed by a 4-hour infusion. The final endpoints were recanalization efficacy at the end of the infusion period and neurological deterioration from intracranial hemorrhage (ICH) within 24 hours of treatment. Rpro-UK treated patients had higher vessel recanalization rates compared to placebo $(57.7 \%$ versus $14.3 \%)$. Furthermore, the incidence of ICH was higher in the rpro-UK group (15.4\% versus $7.1 \%)$. Overall, PROACT I was the first organized trial proving the safety and efficacy of IA thrombolysis for the management of acute ischemic stroke.

PROACT II was a subsequent phase III clinical trial that studied the safety and efficacy of rpro-UK in a larger patient population $(n=180) .{ }^{23}$ This randomized, controlled clinical trial treated patients with MCA occlusion within 6 hours of symptom onset with either 9 $\mathrm{mg}$ of IA rpro-UK and heparin infusion $(n=121)$ or heparin infusion alone $(n-59)$. The study's primary endpoint was the 90-day patient neurological disability based on the modified Rankin score scale. Secondary outcomes included mortality, vessel recanalization, and neurological deterioration from the development of $\mathrm{ICH}$. Patients who received IA rpro-UK had significantly lower Rankin scores at the 90-day endpoint compared to heparin only treated patients. Furthermore, the MCA racanalization and mortality rates favored the rpro-UK group as opposed to the control group $(66 \%$ versus $18 \%)$. Albeit a higher incidence of ICH in the rpro-UK group $(10 \%$ as opposed to $2 \%$ in the control group), the PROACT II multicenter trial demonstrated that the use of IA chemical thrombolysis in acute ischemia of the anterior circulation leads to radiographic and clinical improvement.

Recently, the MELT Japanese study group investigated the IA administration of UK in the setting of MCA stroke within 6 hours of onset.24 Although the study showed favorable 90day functional outcome in the UK-treated patients with respect to controls, results did not reach statistical significance. Unfortunately, the investigation was aborted prematurely 
following the approval of intravenous r-TPA in Japan for the treatment of acute ischemic stroke.

The optimal window for IA thrombolysis in the anterior circulation has been investigated in multiple clinical trials. Overall, results show that IA treatment of acute MCA infarction outweighs potential hemorrhagic risks when implemented within a 6-hour window from symptom onset. ${ }^{15}$ Theron et al investigated the efficacy of IA thrombolysis in patients with acute internal carotid artery (ICA) occlusion as it related to the timing of treatment and angiographic location. ${ }^{25}$ Based on his work, IA fibrinolysis of the MCA should be performed within 6 hours from ischemia onset, when the occlusion involves the horizontal segment of the MCA extending into the lenticulostriate arteries. Treatment complications, mainly hemorrhagic incidence, increase significantly beyond this optimal time-frame. However, if the occlusion does not involve the horizontal MCA segment and the lenticulostriate arteries, then the treatment window can be extended to 12 hours following symptoms. ${ }^{15}$ The paucity of collateral circulation in the lenticulostriate arteries, as well as their distal distribution, both contribute to their sensitivity to ischemia in the setting of acute stroke. When initiating endovascular intra-arterial thrombolysis, the operator should account for time required to perform the procedure. Considering that the average intervention time varies from 45 to 180 minutes, high-risk patients should be treated within 4-5 hours from ischemia onset. ${ }^{26-28}$

\subsubsection{Internal carotid artery}

Occlusions of the proximal ICA (extra-cranial) generally have a better prognosis than intracranial occlusions. The presence of external-internal carotid collateral flow and the anastomosis at the circle of Willis account for this observation. Patients with insufficient extracranial-intracranial anastomoses or an incomplete circle of Willis may be predisposed to developing significant neurological symptoms. These patients are potential candidates for IA intervention. In these cases, mechanical thrombolysis, in addition to pharmacological thrombolysis, is of paramount importance for recanalization. In a 25-patient series, Jovin and colleagues demonstrated successful revascularization in $92 \%$ of patients following thrombolysis and ICA stenting. ${ }^{29}$

Intracranial ICA acute occlusions have a dismal natural history and overall prognosis. Negative prognostic factors include distal ICA distribution involving the M1 and A1 segments (" $\mathrm{T}$ " occlusion) and poor neurological presentation. Furthermore, as observed by Bhatia et al, recanalization following IV r-tPA in patients with T occlusion is the lowest at $4.4 \% 30$. Arnold and colleagues presented a series of 24 patients with distal ICA occlusions treated with IA urokinase. Favorable 3-month functional outcome was present in only $16 \%$ of patients, and the mortality rate was approximately $42 \% .31$ Adjuvant mechanical assistance with devices for balloon angioplasty, clot retrieval, and vessel stenting enhance the probability of vessel recanalization (Fig. 1). Flint et al published a series of 80 patients with ICA occlusion who were treated with combinations of the Merci retriever (Concentric Medical, Mountain View, California) with or without adjunctive endovascular therapy. Recanalization rates were higher in the combination group (63\%) as opposed to the Merci group (53\%). At a 3-month follow-up, $25 \%$ of patients had a good neurological outcome, with their age being a positive predictive indicator. ${ }^{32}$ Overall, these results are encouraging, and IA intervention in select cases of acute ICA occlusion should be considered. 


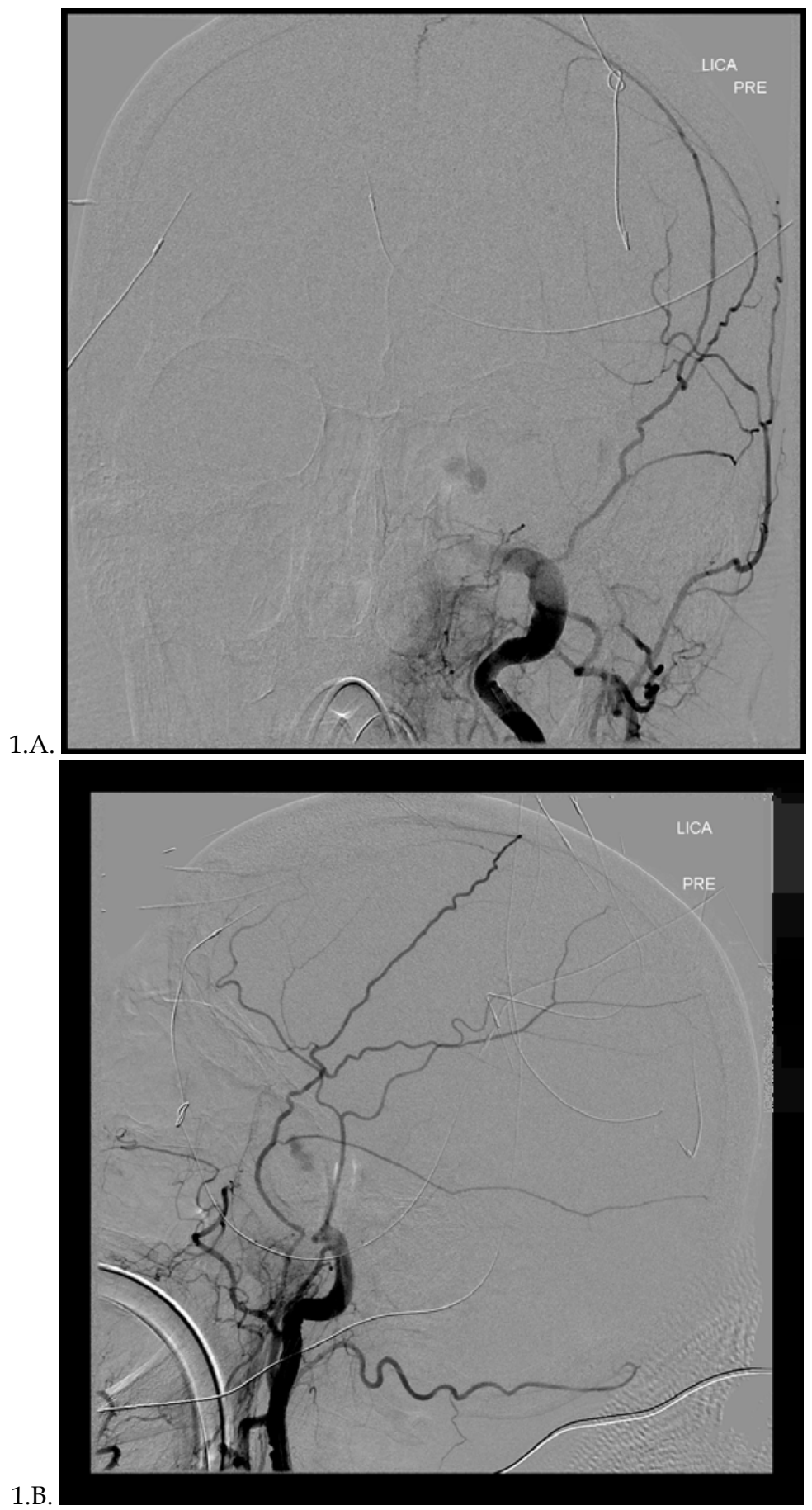




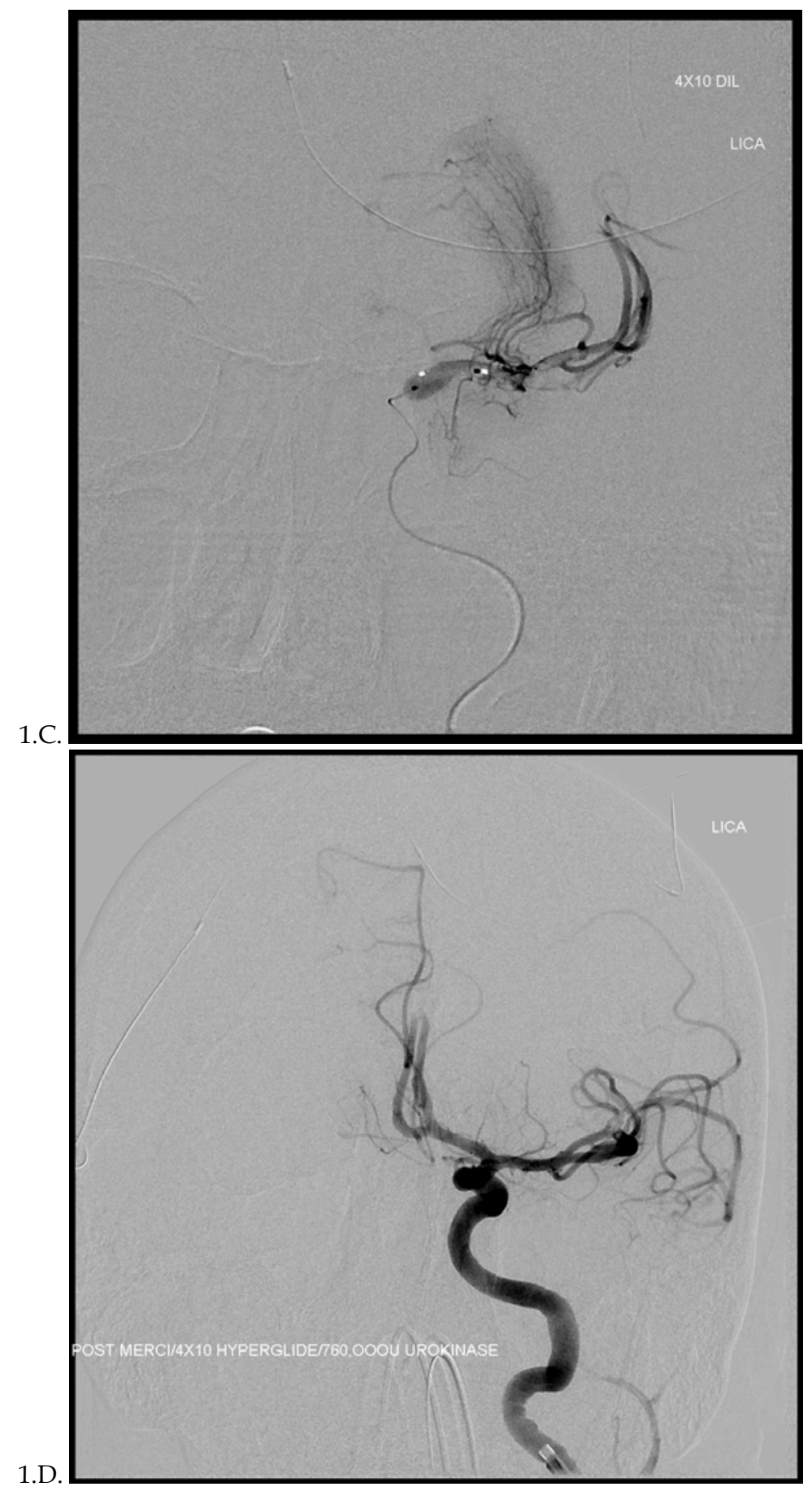




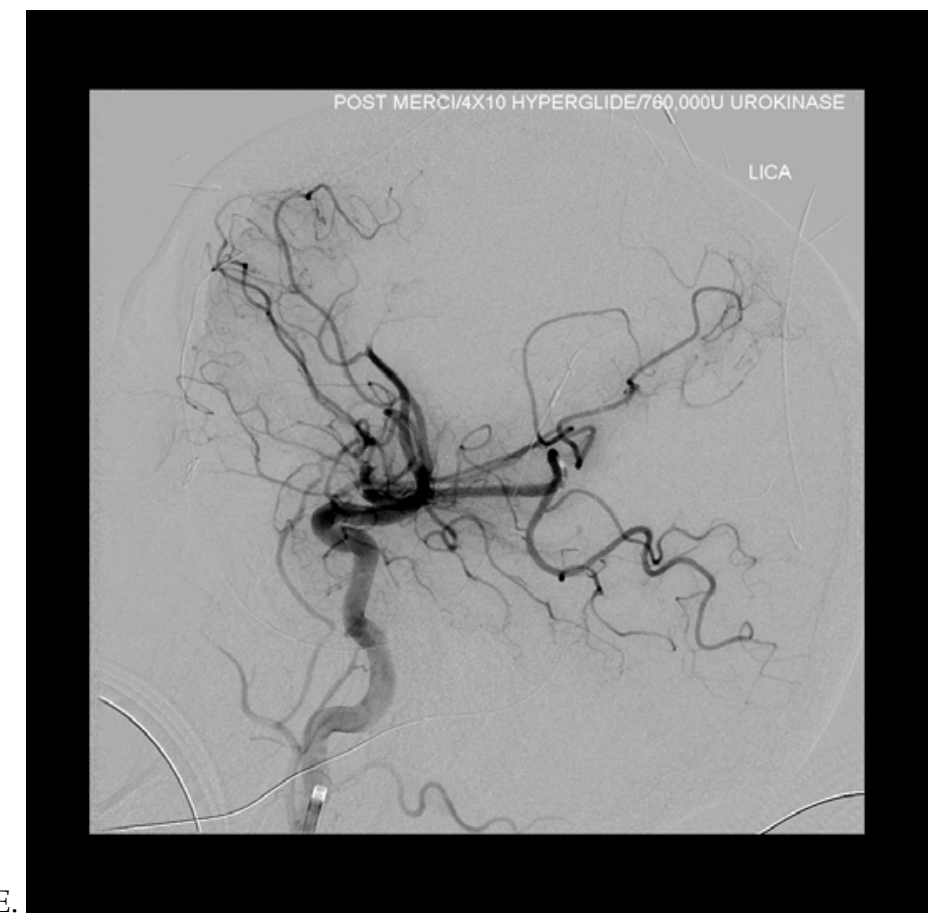

Fig. 1. A-E. Acute left ICA occlusion. The patient presented 6 hours following onset of global aphasia and R hemiplegia. A-B. Mid-arterial digital subtraction angiogram of left ICA artery showing complete occlusion of the distal ICA (T occlusion), frontal and lateral views.

C. Frontal view of balloon angioplasty and recanalization of the distal left ICA.

D-E. Frontal and lateral views of left ICA angiograms following mechanical and chemical recanalization with balloon angioplasty, Merci device, and administration of of Urokinase.

\subsubsection{Central retinal artery}

Occlusion of the Central Retinal Artery (CRA) is an ophthalmologic emergency with a natural history that leads to loss of vision. Conventional medical therapy includes ocular massage, carbohydrate inhibitors, inhalation of carbogen mixture, paracentesis, topical betablockers, aspirin, and intravenous heparin. ${ }^{15}$ However, the limited efficacy of all these therapies made acute CRA occlusion a potential candidate for endovascular management.

Several studies have documented successful vessel recanalization with visual improvement compared to controls. In most studies, IA alteplase is most commonly used within 4-6 hours from symptom onset. The agent is infused via supraselective catheterization of the ophthalmic artery. Padolecchia and colleagues showed that intervention within 4.5 hours of ischemic onset leads to visual improvement in all patients. ${ }^{33}$ Studies performed by Arnold, Aldrich, Noble and their colleagues showed visual improvement in a significant amount of patients treated with IA thrombolysis that ranged from $22 \%$ to $93 \%$ compared to much lower conventionallytreated controls $34-36$. The IA agent was r-tPA or urokinase and the treatment time varied from 6 to 15 hours from symptom onset. Ischemic and hemorrhagic complications were either not present (Arnold, Aldrich) or occurred at significantly low rates (Noble). 


\subsection{Posterior circulation}

Acute basilar artery (BA) occlusion is a life-threatening event that poses a significant therapeutic challenge. The natural progression of untreated BA occlusion has mortality rates ranging from $86 \%$ to $100 \% .15$ The rare incidence of this disease, less than $10 \%$ of acute ischemic strokes, could account for the lack of significant randomized controlled studies in the topic. Several meta-analyses of case reports and case series reflect the severity of the disease. In a series of nearly 300 patients, Furlan and Higashida reported an IA recanalization rate of $60 \%$, and mortality rates of $31 \%$ in at least partially recanalized patients as opposed to $90 \%$ in nonrecanalized patients. ${ }^{37}$ Lindsberg and Mattle compared BA occlusion treatment with IV or IA thrombolysis. They found that although recanalization rates were higher with IA treatement (65\% versus $53 \%)$, dependency or death rates were equal between the two groups $(76-78 \%)$. Overall, $22 \%$ of treated patients had good outcomes, as opposed to only $2 \%$ of untreated individuals. Therefore, emergent thrombolysis via either technique is of paramount importance to the survival of this patient population.

The timing of treatment initiation in relation to symptom onset is a controversial topic. Theoretically, the same treatment restrictions apply as in the anterior circulation, however, in practice, the therapeutic window can be successfully extended beyond 6 hours. In our institution, we have achieved favorable clinical outcomes in patients treated up to 12 hours from symptom onset. Between 12 and 18 hours, incidence of hemorrhagic conversion is more significant, and treatment is rarely extended beyond the 24-hour window. In the Basilar Artery International Cooporation Study (BASICS), 624 patients with radiographically confirmed occlusion of the BA were enrolled in nearly 50 centers over a 5-year period. ${ }^{38}$ All patients $(n=41)$ treated with IA or IV thrombolytics beyond 9 hours from symptom onset had a poor reported outcome.

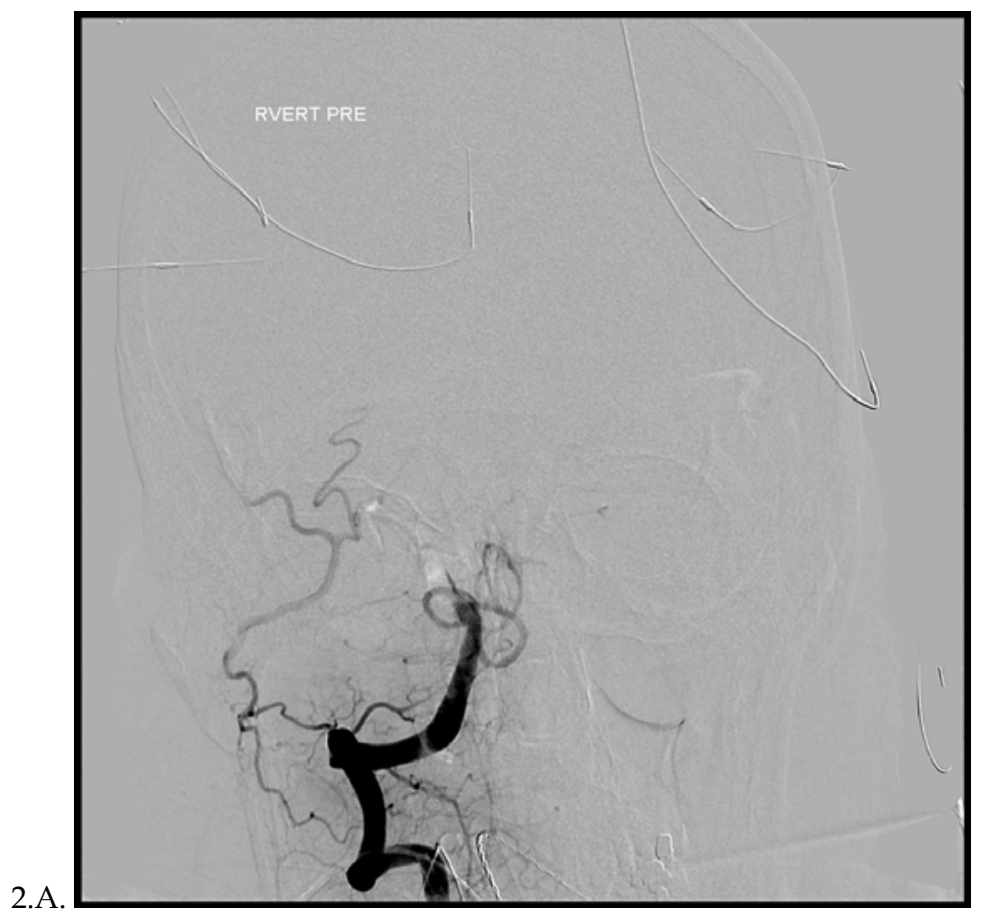




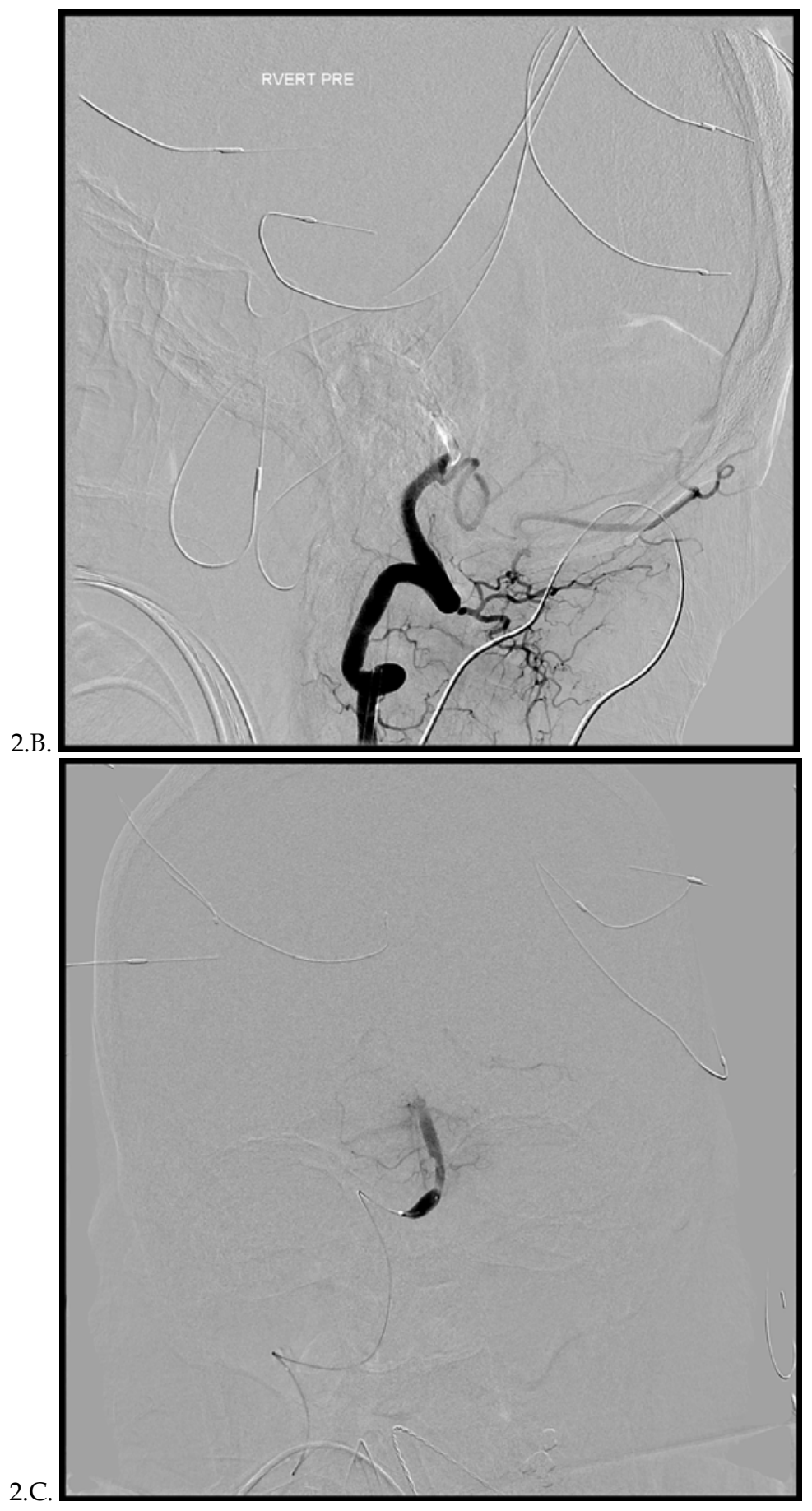




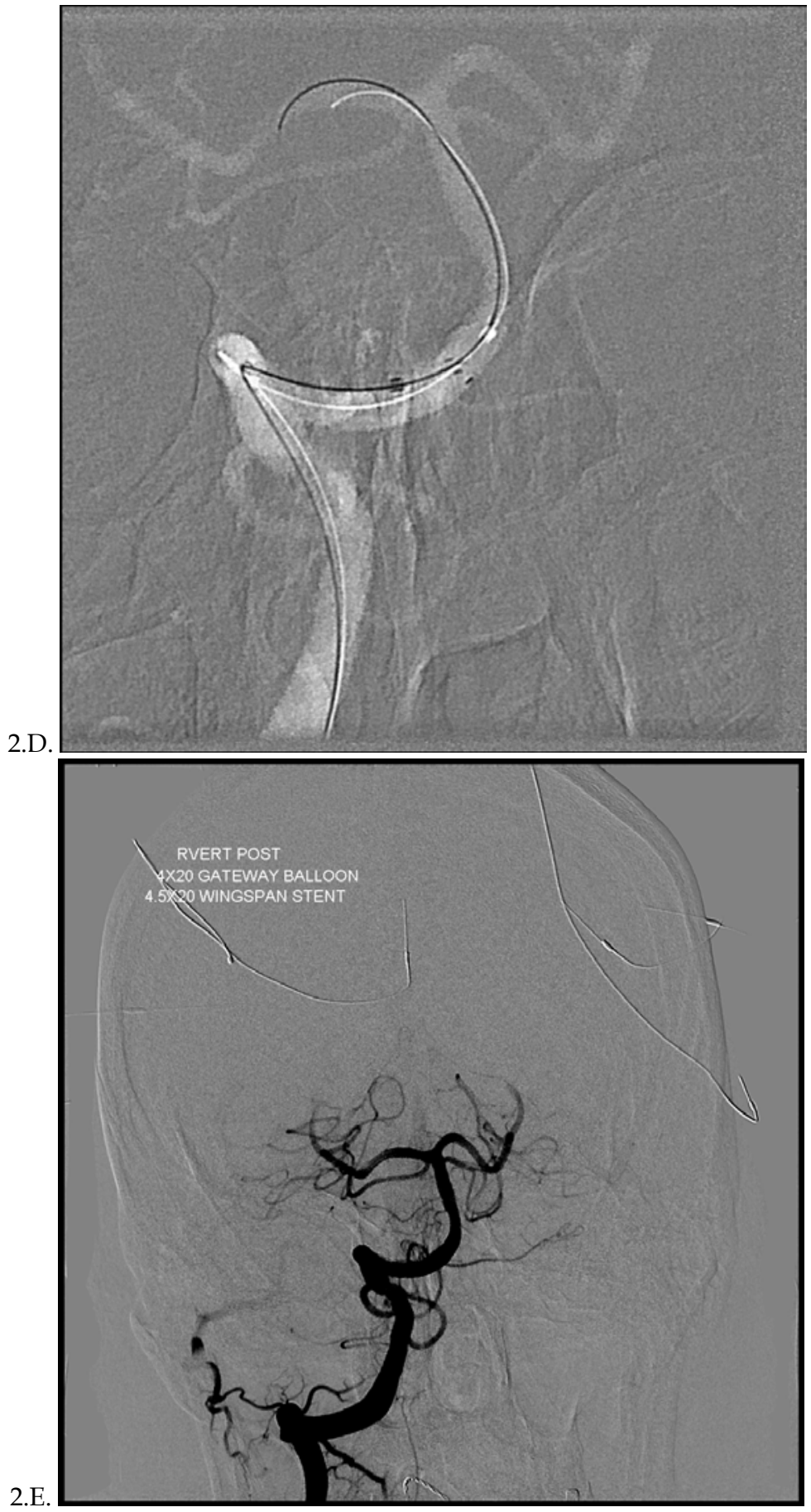




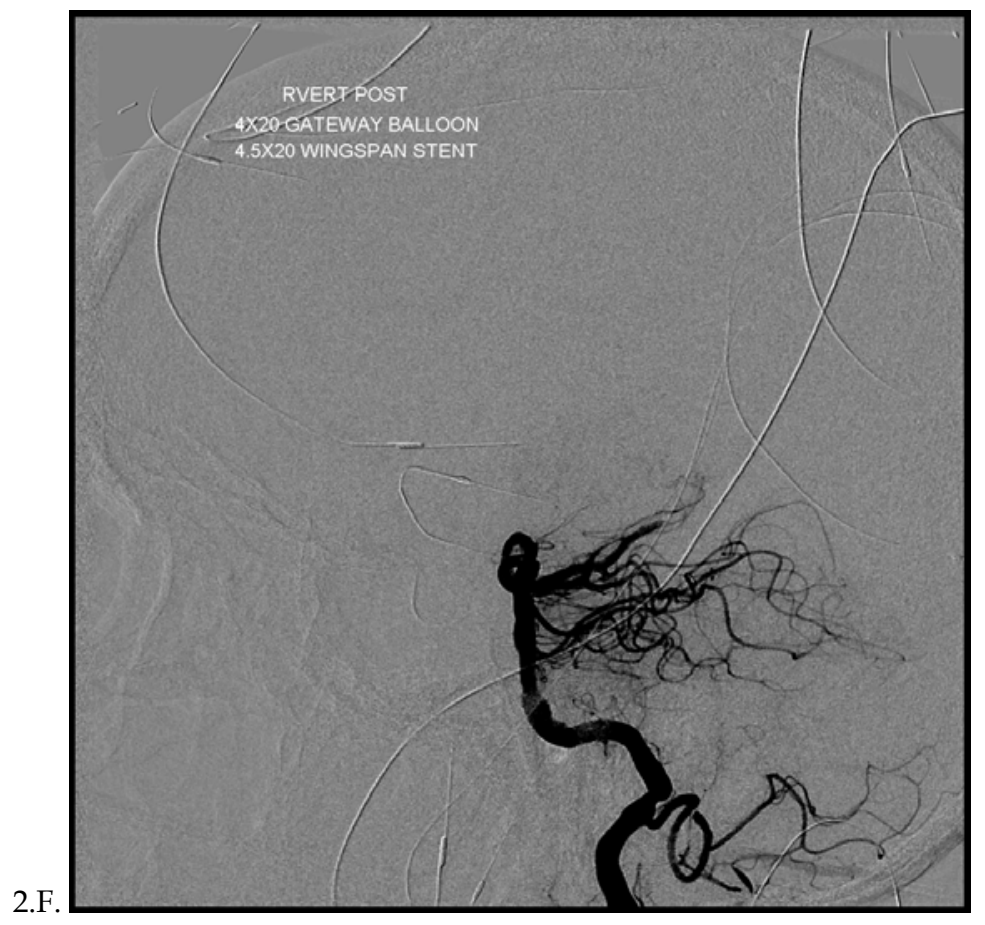

Fig. 2. A-F. Acute right vertebro-basilar occlusion. A-B. Mid-arterial digital subtraction angiogram of the right vertebral artery (dominant) showing complete occlusion with no distal filling of the basilar artery, frontal and lateral views. C. Frontal view of balloon angioplasty of the right vertebro-basilar junction. D. Road map during deployment of Wingspan stent at the vertebro-basilar level. E-F. Frontal and lateral views of right vertebral artery mid-arterial angiograms depicting vessel recanalization following mechanical thrombolysis.

Recent advances in mechanical and pharmacological approaches to endovascular therapies may increase BA recanalization rates and improve patient outcome (Fig. 2). In a metaanalysis of 164 patients with BA occlusion over a 10-year period, Levy et al reported several predictive factors in treatment consideration. ${ }^{39}$ Factors with a negative prognostic value were coma at initial presentation, failure of vessel recanalization, and proximal vessel occlusion. Distal BA occlusions are more commonly embolic in nature and therefore have a better response to thrombolytic agents.

\section{Intra-arterial mechanical thrombolysis}

The use of mechanical endovascular devices for thrombolysis is emerging as a powerful adjuvant, or even an alternative to chemical thrombolysis. In their multi-center review, Gupta and colleagues have demonstrated that multimodality approach with chemical and mechanical thrombolysis leads to higher recanalization rates ${ }^{40}$. The mechanical disruption of the arterial clot has several advantages to IA management of acute stroke.16 First, it increases the working surface area for thrombolytic agents thereby enhancing their efficacy. Even partial removal of clot via retrieval or thromboaspiration techniques lessens the 
concentration of IA agent required to dissolve the remainder pieces. As a result, the risk of $\mathrm{ICH}$ is further decreased and the treatment window could be extended beyond the 6-hour limit. Mechanical thrombolysis provides patients with contraindications to anticoagulation with a reasonable alternative to endovascular therapy.

The use of mechanical thrombolysis is associated with several associated risks. The endovascular trauma to the blood vessel could cause endothelial damage, permanent vascular injury, and ultimately vessel rupture, especially in old friable vessels. The technical skills needed for the endovascular navigation of such devices, especially through severely occluded segments, are substantial, and require rigorous training. Finally, the dislodged clot material could become an embolic source, exposing the already compromised distal circulation to additional ischemic risks.

Overall, the multiple advantages of mechanical endovascular devices have revolutionized current therapies of acute ischemic stroke, and are safe adjuvant and/or alternatives to chemical thrombolysis in experienced hands. The conceptual basis of such devices can be broadly categorized into the following categories: thrombectomy, thromboaspiration, thrombus disruption, augmented fibrinolysis, and thrombus entrapment. ${ }^{16}$

\subsection{Endovascular thrombectomy}

Devices under this category apply a constant force to the clot material at its proximal or distal end and facilitate clot removal. Proximal end forces are applied through grasp-like attachments, whereas distal end forces are applied via basket-like devices. The advantage of these devices is their decreased association with embolic material since there is no attempt for mechanical clot disruption. Some of the most widely used examples are the Merci retriever (Concentric Medical, Mountain View, California), the Neuronet device (Guidant, Santa Clara, California), the Phenox clot retriever (Phenox, Bochum, Germany), the Catch thrombectomy device (Balt Extrusion, Montmorency, France), and the Alligator retrieval device (Chestnut Medical Technologies, Menlo Park, California). ${ }^{16}$ The Merci device became FDA-approved in 2004 for the endovascular clot retrieval in acute ischemic stroke. ${ }^{41}$ It is a flexible nitinol wire with coil loops that incorporate into the clot and facilitate retrieval. Recent analysis of the Mechanical Embolus Removal in Cerebral Ischemia (MERCI) and Multi Merci trials showed that patients with M2 occlusions had higher recanalization rates, decreased procedure duration and similar complication rates with M1 occlusion patients ${ }^{42}$. In a recent study that investigated the efficacy of current thrombectomy mechanisms, the Merci, Phenox, and Catch devices presented equal results with clot mobilization and retrieval.43

\subsection{Endovascular thromboaspiration}

The functioning mechanism in this category utilizes an aspiration technique, which is suited for fresh non-adhesive clots. These devices also have the advantage of fewer embolic material and decreased vasospasm. Some examples in this category are the Penumbra system (Penumbra, Alameda, California) and the AngioJet system (Possis Medical, Minneapolis, Minnesota).16 The Penumbra system includes a reperfusion catheter that aspirates the clot and a ring-shaped retriever (Fig. 3). The favorable results of a prospective multi-center trial conducted in the United States and Europe led to the approval of the device by the FDA for the endovascular treatment of acute ischemic stroke in 2008.44 The AngioJet system uses a high-pressure saline jet for clot agitation and an aspiration catheter for retrieval. Technical difficulties with endovascular navigation resulting in vessel injury led to the premature discontinuation of its trial in acute ischemic stroke patients. ${ }^{45}$ 


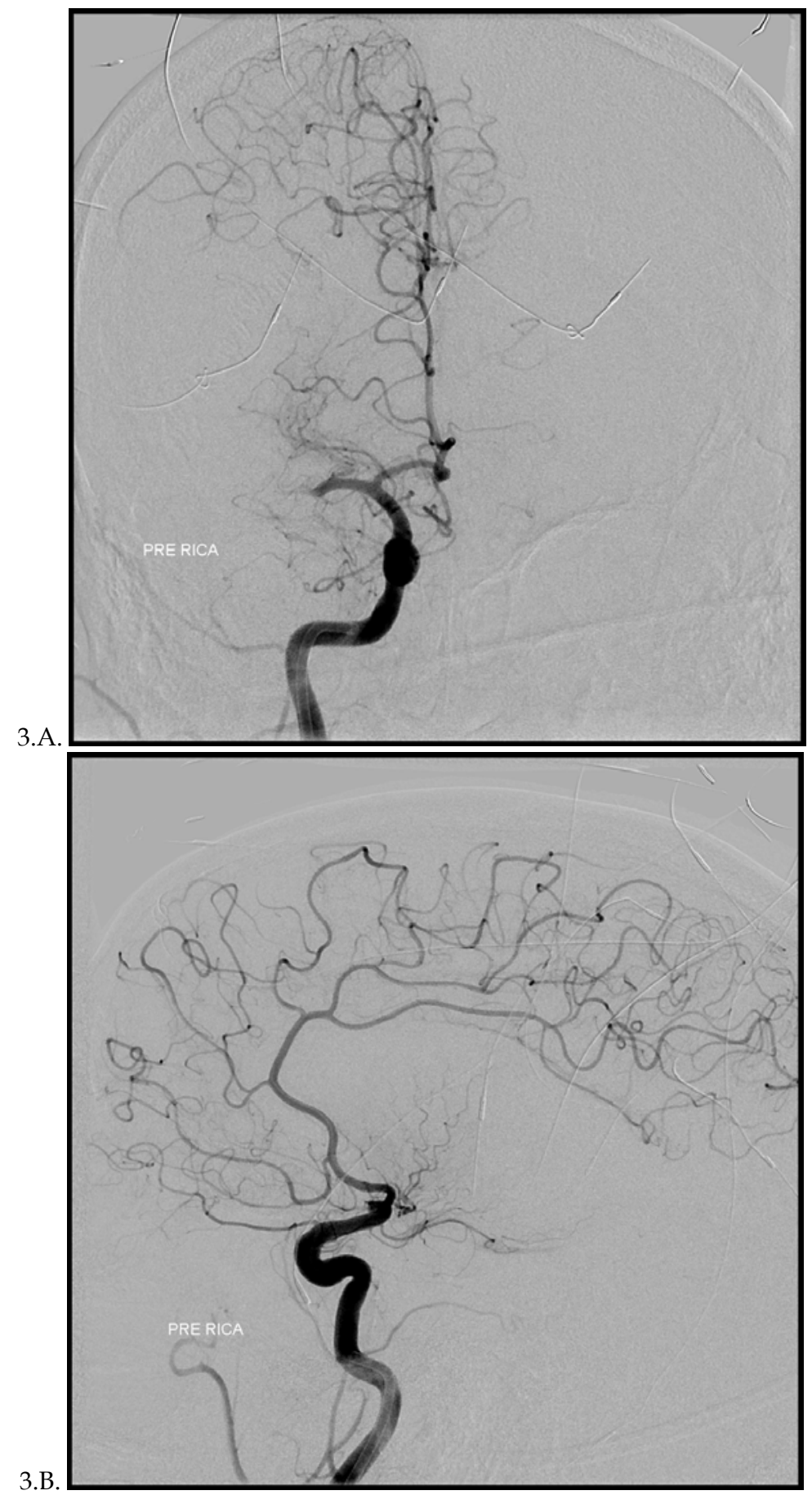




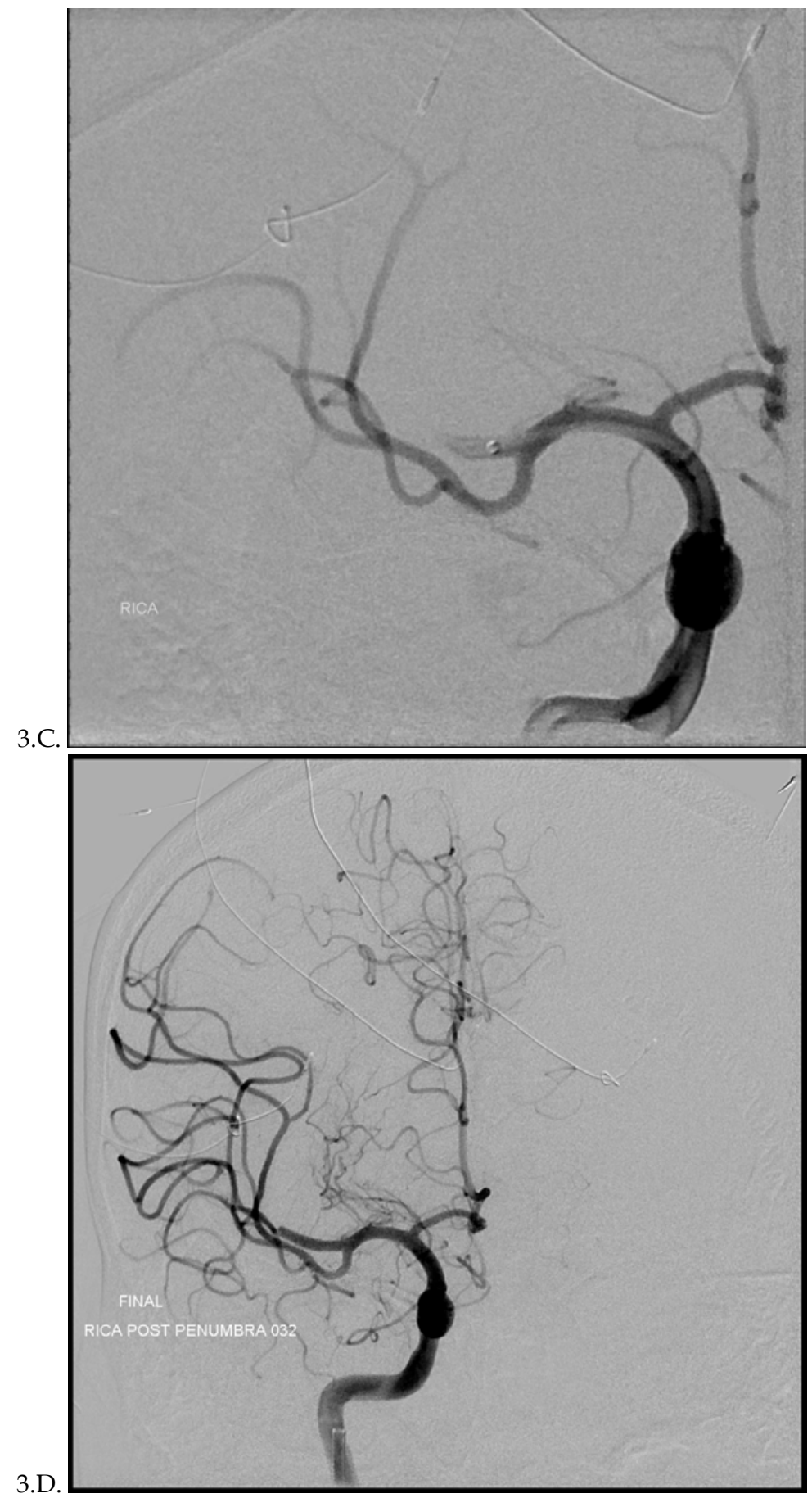




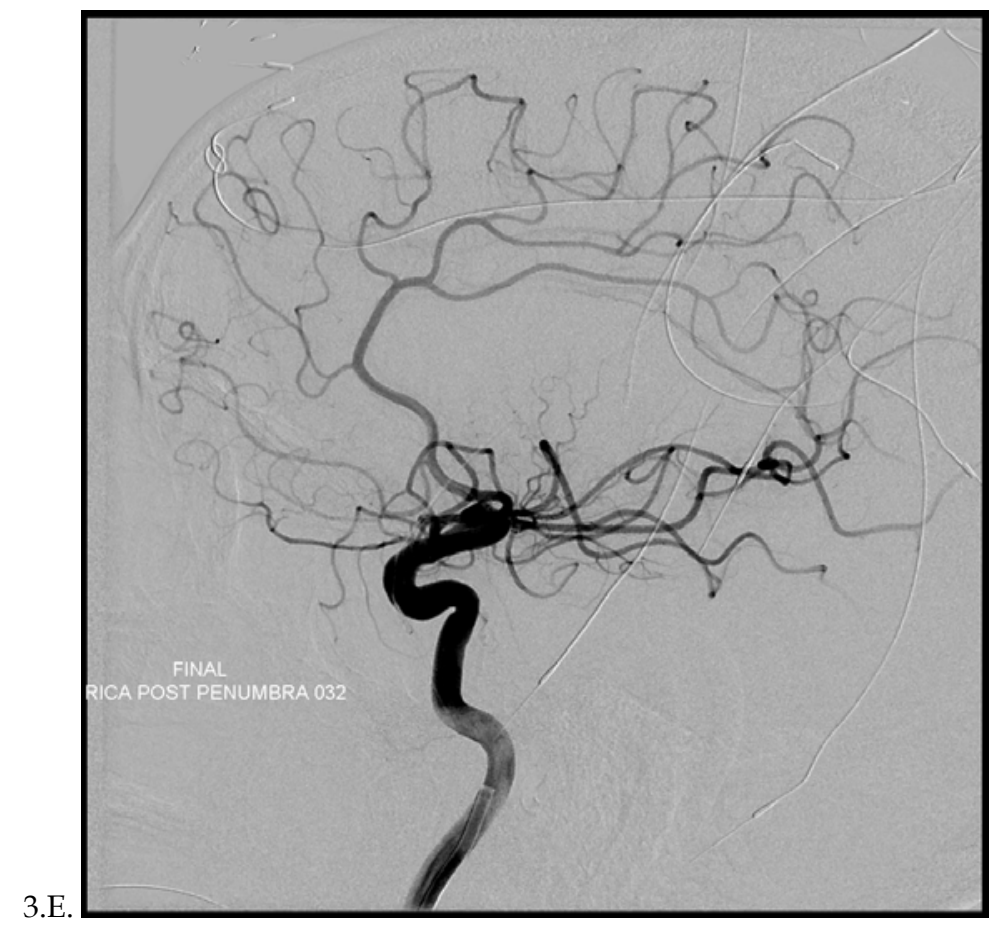

Fig. 3. A-E. Acute right MCA occlusion. The patient presented 4 hours after an acute event of MCA occlusion. A-B. Mid-arterial digital subtraction angiogram of right ICA shows complete MCA occlusion at the level of the bifurcation, frontal and lateral views.

C. Mechanical thrombolysis with Penumbra device showing recanalization of the superior M2 division in a frontal high magnification view. D-E. Frontal and lateral views of right ICA angiograms following MCA mechanical recanalization.

\subsection{Thrombus disruption}

In this category, mechanical disruption of the clot is accomplished via a microguidewire or a snare. Some devices utilizing this mechanism are the EPAR (Endovasix, Belmont, California) and the LaTIS laser device (LaTIS, Minneapolis, Minnesota). ${ }^{16}$ The potential endothelial damage with resultant vessel injury, and genesis of embolic material make these devices less favorable in the setting of acute ischemic stroke.

Traditional balloon inflation techniques could also cause central intra-arterial clot disruption and vessel recanalization (Fig. 4). The balloon is positioned across the vascular filling defect and gently inflated. Typically, a Hyperglide balloon (ev3 Neurovascular, Toledo, CA) is utilized for this technique. The final revascularization result and residual clot burden determine the possibility of additional stenting across the lesion.

\subsection{Augmented fibrinolysis}

These devices, such as the MicroLysUS infusion catheter (EKOS, Bothell, Washington), utilize a sonographic micro-tip to facilitate thrombolysis through ultrasonic vibration. ${ }^{16}$ As a 
result, clot removal is augmented without any additional fragment embolization to the distal circulation. Recent studies show a favorable outcome with the use of such devices for the endovascular management of acute ischemic stroke. ${ }^{46,47}$

\subsection{Thrombus entrapment}

The underlying mechanism of these devices utilizes a stent to recanalize the occluded vessel and therefore trap the clot between the stent and vessel wall. Besides their use at the site of occlusion, stents could recanalize proximal vessels (such as the extracranial ICA) to allow device navigation to the site of pathology. Stents can be deployed via a balloon mechanism or could be self-expandable. The latter are becoming increasingly popular due to their flexibility and ease of navigation. They include the Neuroform stent (Boston Scientific, Natick, Massachusetts), the Enterprise stent (Cordis, Miami Lakes, Florida), the LEO stent (Balt Extrusion, Montmorency, France), the Solitaire/Solo stent (ev3, Irvine, California), and the Wingspan stent (Boston Scientific). The first 4 stents are utilized in stent-assisted coiling of wide-neck aneuryms, whereas the Wingspan is the only stent approved for intracranial treatment of atherosclerotic disease. ${ }^{16}$ Their use in acute ischemic events has been investigated in several trials ${ }^{48-50}$. Kim and colleagues reported recanalization rates as high as $71.4 \%$ in acute ischemic stroke with the use of Neuroform stent in 14 patients ${ }^{48}$. In two studies investigating the Neuroform and Wingspan stents, recanalization rates ranged from $67 \%$ to $89 \%$ and early follow-up (mean of 8 months) showed small (5\%) or no restenosis rates. 51,52

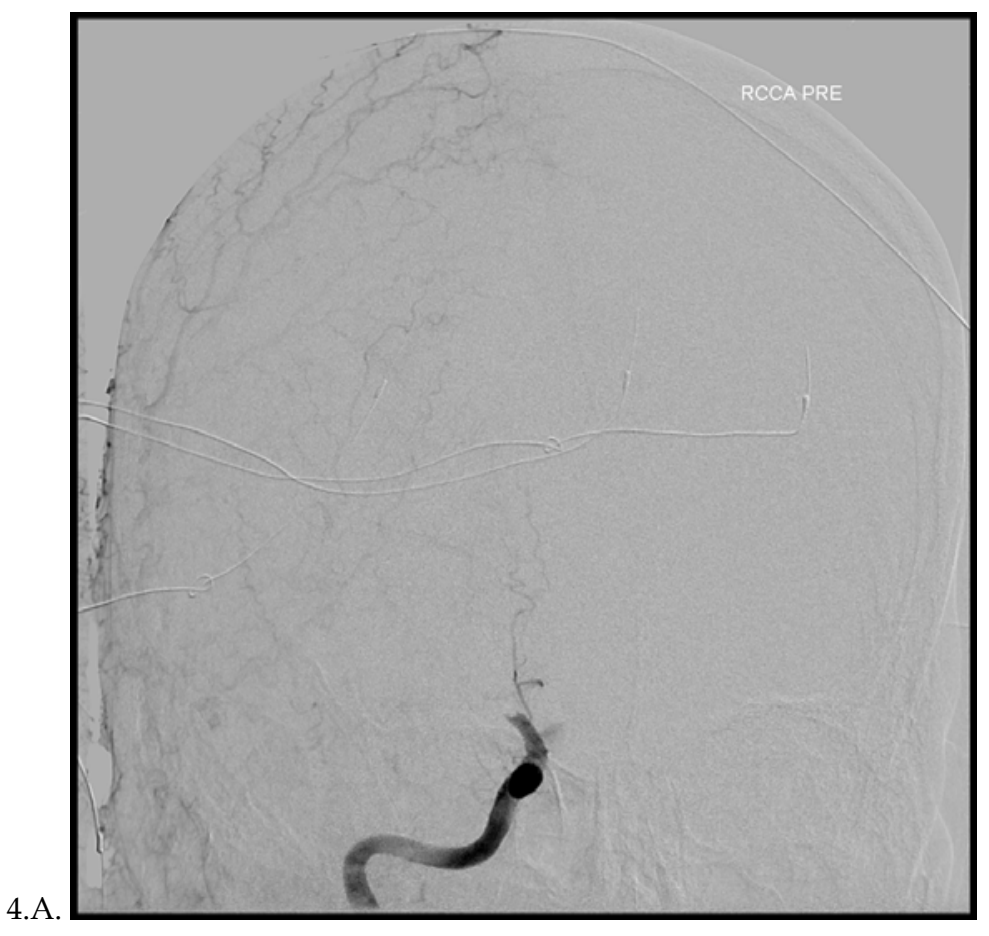




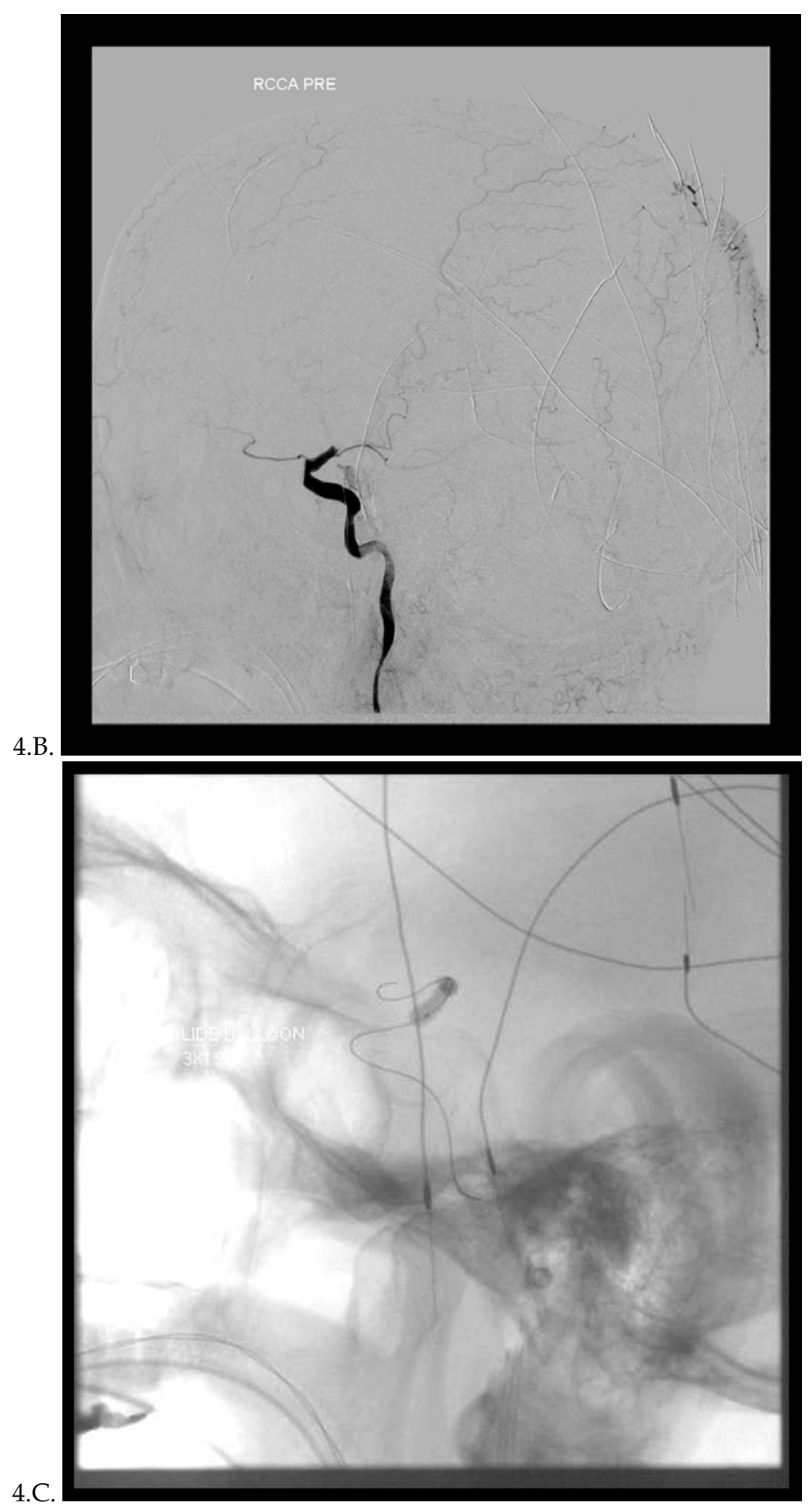




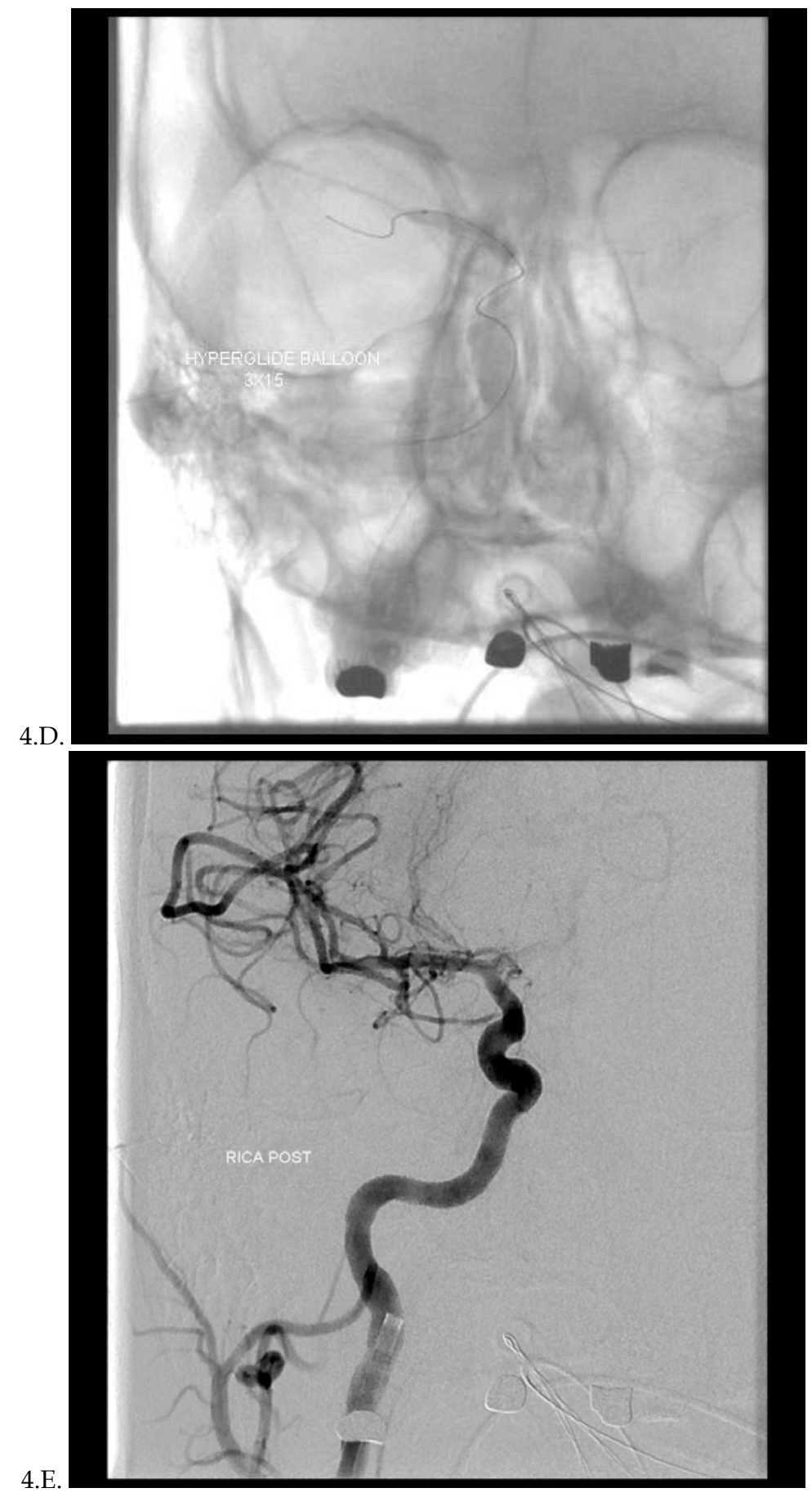




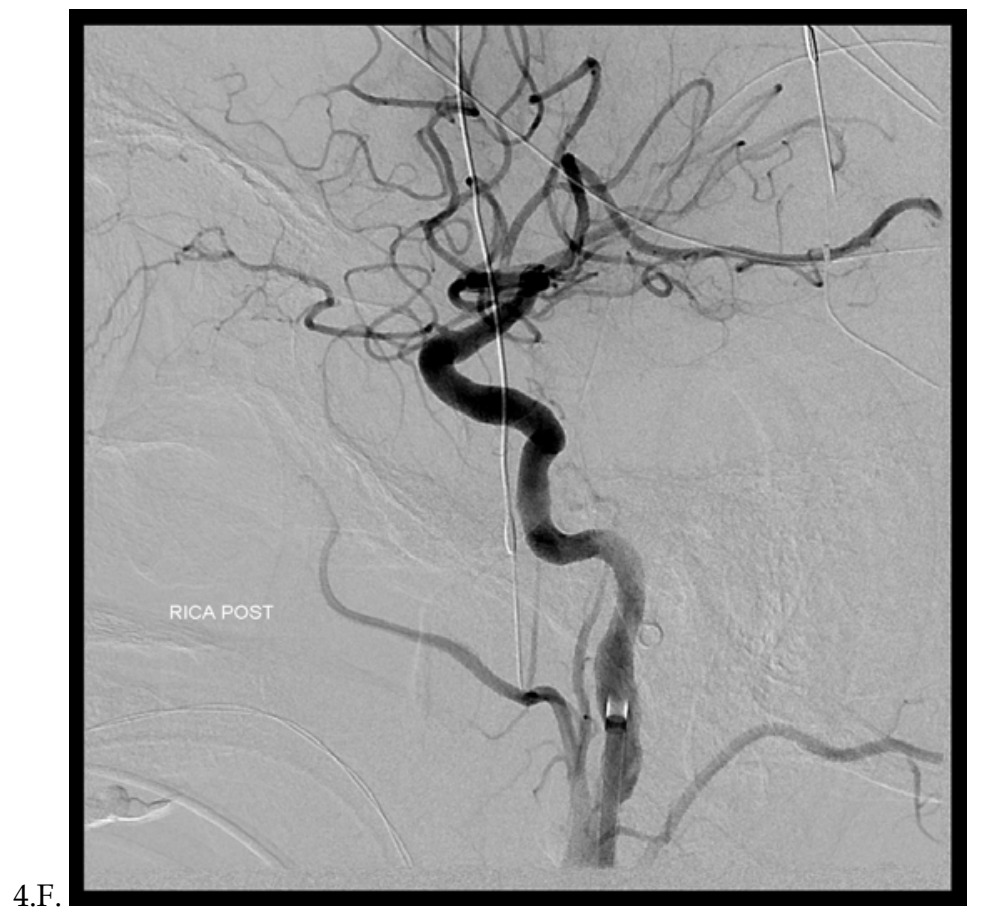

Fig. 4. A-F. Acute right ICA occlusion. The patient presented 5 hours after an acute event of left hemiplegia. A-B. Mid-arterial digital subtraction angiogram of right CCA shows complete ICA occlusion at the level of the ophthalmic artery, frontal and lateral views.

C-D. Balloon angioplasty across the lesion with a Hyperglide $3 \times 15 \mathrm{~mm}$ balloon, frontal and lateral native angiographic views. E-F. Frontal and lateral views of right ICA angiograms following ICA mechanical recanalization.

\section{Alternative reperfusion strategies}

Cerebral reperfusion during acute ischemic stroke can be augmented via alternative strategies that utilize an anterograde or retrograde route. Anterograde reperfusion can be facilitated systemically with vasopressors leading to global reperfusion by increasing the mean arterial blood pressure. Retrograde reperfusion can be facilitated with a transarterial or transvenous approach. The transarterial approach involves the endovascular deployment of the NeuroFlo device (CoAxia, Maple Grove, Minnesota). This dual balloon catheter allows for partial occlusion of the aorta above and below the level of the renal arteries, therefore diverting flow away from the systemic and toward the cerebral circulation.53 Several clinical trials are currently underway investigating the safety and efficacy of NeuroFlo and similar devices.

Transvenous retrograde reperfusion is an experimental technique with potential benefit in acute ischemic stroke. Animal studies suggest that diversion of blood from the femoral artery into the transverse venous sinuses via transvenous catheters could lower infarction size and improve neurological outcome in the setting of acute cerebrovascular ischemia.54 Further investigational human trials are required prior to introducing such a novel concept to current stroke therapies. 


\section{Future directions}

Advances in knowledge about pharmacology, endovascular biomechanics, and endothelial properties are stimulating research on new diagnostic and therapeutic tools in the management of acute ischemic stroke. Currently there are several clinical trials targeting neuroendovascular therapy. ${ }^{21}$ The Interventional Management of Stroke Study III (IMS III) is a phase III multicenter clinical trial that continues the investigation of combined IA and IV therapies in the management of acute stroke. The SYNTHESIS Expansion trial is a phase III clinical study that compares the safety and efficacy of IV thrombolysis to IA chemical and mechanical thrombolysis. Future studies may include the individual comparison of mechanical devices versus intravenous thrombolytics 55 .

Multiple studies are investigating the safety and efficacy of new generation endovascular devices, such as the Safety and Efficacy of NeuroFlo Technology in Ischemic Stroke (SENTIS). The neurological outcomes of optimal medical management versus IA thrombolysis are examined in clinical trials such as RETRIEVE (Randomized Trial of Endovascular treatment of Acute Ischemic Stroke Versus Medical Management) and PISTE (Pragmatic Ischemic Stroke Thrombectomy Evaluation). Extending the timing of endovascular intervention is being evaluated in conjunction with new radiographic techniques. Examples include the DWI and CTP Assessment in the Triage of Wake-Up and Late Presenting Strokes Undergoing Neurointervention Trial, and the MR Imaging and Recanalization of Stroke Clots During Embolectomy Trial.21

These and several other upcoming trials will hopefully provide sufficient clinical data for the FDA approval of IA agents, the introduction of new endovascular devices, and other adjunctive therapies for the management of the acute stroke patient.

\section{Conclusion}

Over the past decade, endovascular intervention has become a mainstay treatment in the setting of acute ischemic stroke. Innovative techniques in both chemical and mechanical intraarterial thrombolysis increase the safety and efficacy of endovascular management and expand its indications in acute cerebral infarction. Additional larger clinical trials are warranted for the improvement of the endovascular care of stroke patients resulting in faster and safer reperfusion mechanisms.

\section{References}

[1] AHA. Heart and Stroke Update. 2010.

[2] Fagan SC, Morgenstern LB, Petitta A, et al. Cost-effectiveness of tissue plasminogen activator for acute ischemic stroke. NINDS rt-PA Stroke Study Group. In: Neurology; 1998:883-90.

[3] Sussman BJ, Fitch TS. Thrombolysis with fibrinolysin in cerebral arterial occlusion. In: Journal of the American Medical Association; 1958:1705-9.

[4] Goyal M, Menon BK, Coutts SB, Hill MD, Demchuk AM, Penumbra Pivotal Stroke Trial Investigators CSP, and the Seaman MR Research Center. Effect of baseline CT scan appearance and time to recanalization on clinical outcomes in endovascular thrombectomy of acute ischemic strokes. In: Stroke; 2011:93-7. 
[5] Vora NA, Gupta R, Thomas AJ, et al. Factors predicting hemorrhagic complications after multimodal reperfusion therapy for acute ischemic stroke. In: AJNR American journal of neuroradiology; 2007:1391-4.

[6] Gönner F, Remonda L, Mattle H, et al. Local intra-arterial thrombolysis in acute ischemic stroke. In: Stroke; 1998:1894-900.

[7] von Kummer R, Meyding-Lamadé U, Forsting M, et al. Sensitivity and prognostic value of early CT in occlusion of the middle cerebral artery trunk. In: AJNR American journal of neuroradiology; 1994:9-15; discussion 6-8.

[8] Wolpert SM, Bruckmann H, Greenlee R, Wechsler L, Pessin MS, del Zoppo GJ. Neuroradiologic evaluation of patients with acute stroke treated with recombinant tissue plasminogen activator. The rt-PA Acute Stroke Study Group. In: AJNR American journal of neuroradiology; 1993:3-13.

[9] Konstas AA, Goldmakher GV, Lee TY, Lev MH. Theoretic basis and technical implementations of CT perfusion in acute ischemic stroke, part 1: Theoretic basis. In: AJNR American journal of neuroradiology; 2009:662-8.

[10] Zacharatos H, Hassan AE, Vazquez G, et al. Comparison of acute nonthrombolytic and thrombolytic treatments in ischemic stroke patients 80 years or older. In: The American journal of emergency medicine; 2011.

[11] McDonagh DL, Olson DM, Kalia JS, Gupta R, Abou-Chebl A, Zaidat OO. Anesthesia and Sedation Practices Among Neurointerventionalists during Acute Ischemic Stroke Endovascular Therapy. In: Frontiers in neurology; 2010:118.

[12] Gupta R. Local is better than general anesthesia during endovascular acute stroke interventions. In: Stroke; 2010:2718-9.

[13] Jumaa MA, Zhang F, Ruiz-Ares G, et al. Comparison of safety and clinical and radiographic outcomes in endovascular acute stroke therapy for proximal middle cerebral artery occlusion with intubation and general anesthesia versus the nonintubated state. In: Stroke; 2010:1180-4.

[14] Bang OY, Saver JL, Kim SJ, et al. Collateral flow predicts response to endovascular therapy for acute ischemic stroke. In: Stroke; 2011:693-9.

[15] Berenstein Alejandro, Lasjaunias Pierre, G. ter Brugge Karel. Surgical neuroangiography. Vol. 2, Clinical and endovascular treatment .... In.

[16] Nogueira RG, Schwamm LH, Hirsch JA. Endovascular approaches to acute stroke, part 1: Drugs, devices, and data. In: AJNR American journal of neuroradiology; 2009:649-61.

[17] Cornu C, Boutitie F, Candelise L, et al. Streptokinase in acute ischemic stroke: an individual patient data meta-analysis : The Thrombolysis in Acute Stroke Pooling Project. In: Stroke; 2000:1555-60.

[18] Lisboa RC, Jovanovic BD, Alberts MJ. Analysis of the safety and efficacy of intra-arterial thrombolytic therapy in ischemic stroke. In: Stroke; 2002:2866-71.

[19] Kaur J, Zhao Z, Klein GM, Lo EH, Buchan AM. The neurotoxicity of tissue plasminogen activator? In: J Cereb Blood Flow Metab; 2004:945-63.

[20] Memon MZ, Natarajan SK, Sharma J, et al. Safety and feasibility of intraarterial eptifibatide as a revascularization tool in acute ischemic stroke. In: J Neurosurg; 2010.

[21] Nogueira RG, Yoo AJ, Buonanno FS, Hirsch JA. Endovascular approaches to acute stroke, part 2: a comprehensive review of studies and trials. In: AJNR American journal of neuroradiology; 2009:859-75.

[22] del Zoppo GJ, Higashida RT, Furlan AJ, Pessin MS, Rowley HA, Gent M. PROACT: a phase II randomized trial of recombinant pro-urokinase by direct arterial delivery 
in acute middle cerebral artery stroke. PROACT Investigators. Prolyse in Acute Cerebral Thromboembolism. In: Stroke; 1998:4-11.

[23] Furlan A, Higashida R, Wechsler L, et al. Intra-arterial prourokinase for acute ischemic stroke. The PROACT II study: a randomized controlled trial. Prolyse in Acute Cerebral Thromboembolism. In: JAMA; 1999:2003-11.

[24] Ogawa A, Mori E, Minematsu K, et al. Randomized trial of intraarterial infusion of urokinase within 6 hours of middle cerebral artery stroke: the middle cerebral artery embolism local fibrinolytic intervention trial (MELT) Japan. In: Stroke; 2007:2633-9.

[25] Theron J, Courtheoux P, Casasco A, et al. Local intraarterial fibrinolysis in the carotid territory. In: AJNR American journal of neuroradiology; 1989:753-65.

[26] Brott T. Thrombolytic therapy. In: Neurologic clinics; 1992:219-32.

[27] Levine SR, Brott TG. Thrombolytic therapy in cerebrovascular disorders. In: Progress in cardiovascular diseases; 1992:235-62.

[28] Barnwell SL, Clark WM, Nguyen TT, O'Neill OR, Wynn ML, Coull BM. Safety and efficacy of delayed intraarterial urokinase therapy with mechanical clot disruption for thromboembolic stroke. In: AJNR American journal of neuroradiology; 1994:1817-22.

[29] Jovin TG, Gupta R, Uchino K, et al. Emergent stenting of extracranial internal carotid artery occlusion in acute stroke has a high revascularization rate. In: Stroke; 2005:2426-30.

[30] Bhatia R, Hill MD, Shobha N, et al. Low rates of acute recanalization with intravenous recombinant tissue plasminogen activator in ischemic stroke: real-world experience and a call for action. In: Stroke; 2010:2254-8.

[31] Arnold M, Nedeltchev K, Mattle HP, et al. Intra-arterial thrombolysis in 24 consecutive patients with internal carotid artery T occlusions. In: J Neurol Neurosurg Psychiatr; 2003:739-42.

[32] Flint AC, Duckwiler GR, Budzik RF, Liebeskind DS, Smith WS, Committee MaMMW. Mechanical thrombectomy of intracranial internal carotid occlusion: pooled results of the MERCI and Multi MERCI Part I trials. In: Stroke; 2007:1274-80.

[33] Padolecchia R, Puglioli M, Ragone MC, Romani A, Collavoli PL. Superselective intraarterial fibrinolysis in central retinal artery occlusion. In: AJNR American journal of neuroradiology; 1999:565-7.

[34] Arnold M, Koerner U, Remonda L, et al. Comparison of intra-arterial thrombolysis with conventional treatment in patients with acute central retinal artery occlusion. In: J Neurol Neurosurg Psychiatr; 2005:196-9.

[35] Aldrich EM, Lee AW, Chen CS, et al. Local intraarterial fibrinolysis administered in aliquots for the treatment of central retinal artery occlusion: the Johns Hopkins Hospital experience. In: Stroke; 2008:1746-50.

[36] Noble J, Weizblit N, Baerlocher MO, Eng KT. Intra-arterial thrombolysis for central retinal artery occlusion: a systematic review. In: Br J Ophthalmol; 2008:588-93.

[37] Furlan A, Higashida, R. Intra-arterial thrombolysis in acute ischemic stroke. In: Stroke: Pathophysiology, Diagnosis, and Management. 4th ed. Philadelphia: Churchill Livingstone; 2004:943-51.

[38] Schonewille WJ, Wijman CA, Michel P, Algra A, Kappelle LJ, Group BS. The basilar artery international cooperation study (BASICS). In: International journal of stroke : official journal of the International Stroke Society; 2007:220-3.

[39] Levy EI, Firlik AD, Wisniewski S, et al. Factors affecting survival rates for acute vertebrobasilar artery occlusions treated with intra-arterial thrombolytic therapy: a meta-analytical approach. In: Neurosurgery; 1999:539-45; discussion 45-8. 
[40] Gupta R, Tayal AH, Levy EI, et al. Intra-arterial thrombolysis or Stent Placement during Endovascular Treatment for Acute Ischemic Stroke Leads to the Highest Recanalization Rate: Results of a Multi-center Retrospective Study. In: Neurosurgery; 2011.

[41] Smith WS, Sung G, Starkman S, et al. Safety and efficacy of mechanical embolectomy in acute ischemic stroke: results of the MERCI trial. In: Stroke; 2005:1432-8.

[42] Shi Z-S, Loh Y, Walker G, Duckwiler GR, Investigators MaM-M. Clinical outcomes in middle cerebral artery trunk occlusions versus secondary division occlusions after mechanical thrombectomy: pooled analysis of the Mechanical Embolus Removal in Cerebral Ischemia (MERCI) and Multi MERCI trials. In: Stroke; 2010:953-60.

[43] Liebig T, Reinartz J, Hannes R, Miloslavski E, Henkes H. Comparative in vitro study of five mechanical embolectomy systems: effectiveness of clot removal and risk of distal embolization. In: Neuroradiology; 2008:43-52.

[44] Bose A, Henkes H, Alfke K, et al. The Penumbra System: a mechanical device for the treatment of acute stroke due to thromboembolism. In: AJNR American journal of neuroradiology; 2008:1409-13.

[45] Nesbit GM, Luh G, Tien R, Barnwell SL. New and future endovascular treatment strategies for acute ischemic stroke. In: Journal of vascular and interventional radiology : JVIR; 2004:S103-10.

[46] Mahon BR, Nesbit GM, Barnwell SL, et al. North American clinical experience with the EKOS MicroLysUS infusion catheter for the treatment of embolic stroke. In: AJNR American journal of neuroradiology; 2003:534-8.

[47] Investigators IIT. The Interventional Management of Stroke (IMS) II Study. In: Stroke; 2007:2127-35.

[48] Kim SM, Lee DH, Kwon SU, Choi CG, Kim SJ, Suh DC. Treatment of acute ischemic stroke: feasibility of primary or secondary use of a self-expanding stent (Neuroform) during local intra-arterial thrombolysis. In: Neuroradiology; 2011.

[49] Mourand I, Brunel H, Vendrell J-F, Thouvenot E, Bonafé A. Endovascular stent-assisted thrombolysis in acute occlusive carotid artery dissection. In: Neuroradiology; 2010:135-40.

[50] Prince EA, Jayaraman MV, Haas RA. Use of self-expanding intracranial stents in the treatment of acute ischemic stroke. In: Journal of vascular and interventional radiology : JVIR; 2010:1755-9.

[51] Levy EI, Mehta R, Gupta R, et al. Self-expanding stents for recanalization of acute cerebrovascular occlusions. In: AJNR American journal of neuroradiology; 2007:816-22.

[52] Zaidat OO, Wolfe T, Hussain SI, et al. Interventional acute ischemic stroke therapy with intracranial self-expanding stent. In: Stroke; 2008:2392-5.

[53] Lylyk P, Vila JF, Miranda C, Ferrario A, Romero R, Cohen JE. Partial aortic obstruction improves cerebral perfusion and clinical symptoms in patients with symptomatic vasospasm. In: Neurol Res; 2005:S129-35.

[54] Frazee JG, Luo X, Luan G, et al. Retrograde transvenous neuroperfusion: a back door treatment for stroke. In: Stroke; 1998:1912-6.

[55] Mazighi M, Amarenco P. Reperfusion therapy in acute cerebrovascular syndrome. In: Curr Opin Neurol; 2011:59-62.

[56] Neurology WGftAAo, Section ACC, Surgery SoN, et al. Performance and training standards for endovascular ischemic stroke treatment. In: AJNR American journal of neuroradiology; 2010:E8-11. 


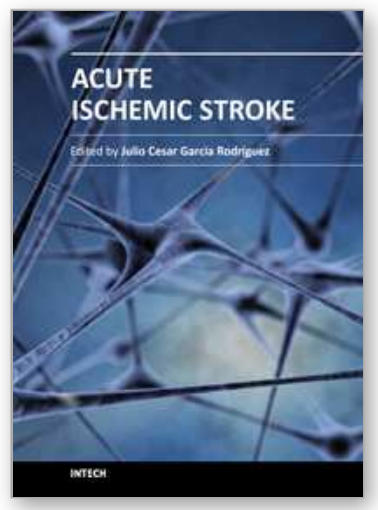

\author{
Acute Ischemic Stroke \\ Edited by Prof. Julio Cesar Garcia Rodriguez
}

ISBN 978-953-307-983-7

Hard cover, 236 pages

Publisher InTech

Published online 18, January, 2012

Published in print edition January, 2012

Despite significant technological advances in recent years, their impact on our overall health and social, wellbeing is not always clear to see. Perhaps, one of the best examples of this can be highlighted by the fact that mortality rates as a result of cerebrovascular diseases have hardly changed, if at all. This places cerebrovascular diseases as one of the most prominent causes of both disability and death. In Cuba, for instance, a total of 22,000 cases of cerebrovascular diseases are reported each year in a country where life expectancy should increase to 80 years in the near future. In such a situation, to have a book that includes in a clear and summarized way, a group of topics directly related to the preclinical investigations advances and the therapeutic procedures for the cerebrovascular disease in its acute phase constitutes a useful tool for the wide range of the contributors to this affection's problems solution. In this group is included students, professors, researchers, and health policy makers whose work represents one of the greatest social and human impact challenges of the XXI century basic and clinical neurosciences.

\title{
How to reference
}

In order to correctly reference this scholarly work, feel free to copy and paste the following:

Stavropoula I. Tjoumakaris, Pascal M. Jabbour, Aaron S. Dumont, L. Fernando Gonzalez and Robert H. Rosenwasser (2012). Endovascular Management of Acute Ischemic Stroke, Acute Ischemic Stroke, Prof. Julio Cesar Garcia Rodriguez (Ed.), ISBN: 978-953-307-983-7, InTech, Available from:

http://www.intechopen.com/books/acute-ischemic-stroke/endovascular-management-of-acute-ischemic-stroke

\section{INTECH}

open science | open minds

\section{InTech Europe}

University Campus STeP Ri

Slavka Krautzeka 83/A

51000 Rijeka, Croatia

Phone: +385 (51) 770447

Fax: +385 (51) 686166

www.intechopen.com

\section{InTech China}

Unit 405, Office Block, Hotel Equatorial Shanghai

No.65, Yan An Road (West), Shanghai, 200040, China

中国上海市延安西路65号上海国际贵都大饭店办公楼405单元

Phone: +86-21-62489820

Fax: $+86-21-62489821$ 
(C) 2012 The Author(s). Licensee IntechOpen. This is an open access article distributed under the terms of the Creative Commons Attribution 3.0 License, which permits unrestricted use, distribution, and reproduction in any medium, provided the original work is properly cited. 